\title{
LETTER
}

\section{Carboxyhemoglobin levels during human inflammation}

\author{
Mirrin Josefien Dorresteijn ${ }^{* 1,2}$ and Peter Pickkers ${ }^{1,3}$ \\ See related research by Fazekas et al., http://ccforum.com/content/16/1/R6, and related letter by Cove and Pinsky, \\ http://ccforum.com/content/16/1/411
}

In agreement with the study by Fazekas and colleagues [1] in a recent issue of Critical Care, an increase in the concentration of carbon monoxide (CO) has been observed after surgery and cardiopulmonary bypass and during sepsis [2]. Although inflammation induces heme oxygenase and the above-mentioned conditions do lead to inflammation, a clear association in humans has not been established, underlining the relevance of the remarks made by Cove and Pinsky [3] in the same issue of Critical Care. We would like to present data that illustrate that inflammation does increase $\mathrm{CO}$ in humans in vivo.

During experimental endotoxemia in humans, a controlled immune response is evoked, leading to increased levels of several pro- and anti-inflammatory markers [4]. Recent experiments demonstrated that, in 38 healthy male volunteers infused with US Standard Reference Endotoxin (National Institutes of Health, Bethesda, USA) obtained from Escherichia coli O:113 at a dose of $2 \mathrm{ng} / \mathrm{kg}$, tumor necrosis factor-alpha concentrations increase at $\mathrm{t}=2$ hours to a median of $610 \mathrm{pg} / \mathrm{mL}$ (interquartile range of 400 to $853 \mathrm{pg} / \mathrm{mL}$; Friedman test $P<0.001$ ) and arterial carboxyhemoglobin levels increase by $42 \%$ at 4 hours after lipopolysaccharide infusion (Friedman test $P=0.0057$ ) (Figure 1). During these experiments, subjects breathed ambient air in a climate-controlled room; therefore, Cove and Pinsky's claim that an increase of $\mathrm{CO}$ is due to an increase in inhalation is unlikely.

Interestingly, the anti-inflammatory effects of $\mathrm{CO}$ have also been studied in this model. Although $\mathrm{CO}$ has had clear beneficial effects in several animal studies, inhaled $\mathrm{CO}$ during experimental endotoxemia failed to influence the inflammatory response in humans [5], making it

\footnotetext{
*Correspondence: m.dorresteijn@ic.umcn.nl

'Department of Intensive Care, Radboud University Nijmegen Medical Centre, Geert Grooteplein-zuid 10, 6525 GA Nijmegen, The Netherlands

Full list of author information is available at the end of the article
}

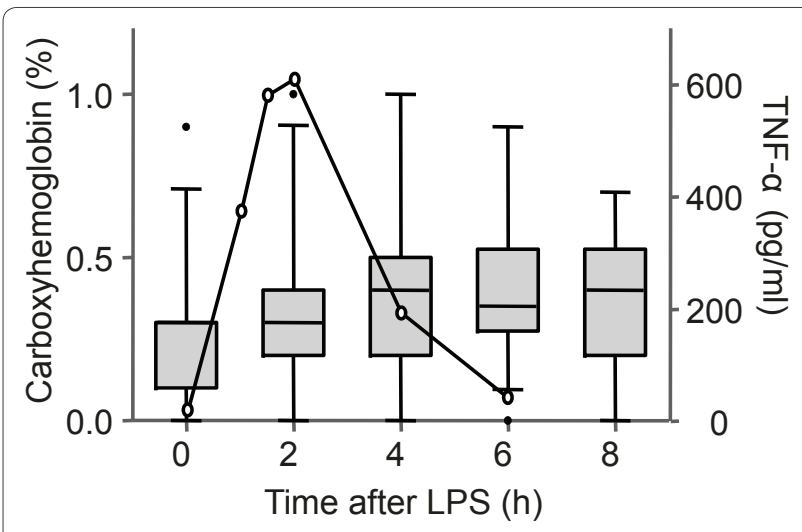

Figure 1. Tumor necrosis factor-alpha (TNF-a) and carboxyhemoglobin levels in arterial blood during experimental human endotoxemia. At $t=0$ hours, 38 healthy male subjects were infused with $2 \mathrm{ng} / \mathrm{kg}$ Escherichia coli endotoxin. Arterial blood was sampled serially to determine concentrations of carboxyhemoglobin (Siemens Rapidlab 348 blood gas analyzer; Siemens Medical Solutions, Munich, Germany) and plasma TNF-a (Bio-plex cytokine assay; Bio-Rad Laboratories, Inc., Hercules, CA, USA, at a Luminex 100; Luminex Corporation, Oosterhout, The Netherlands). Carboxyhemoglobin levels are presented by boxplots, and whiskers indicate 5 th to 95th percentiles. TNF-a is presented as median (black line); for clarity, interquartile range is omitted. Statistical analysis was performed by using the Friedman test (carboxyhemoglobin: $P=0.0057$; TNF-a: $P<0.001)$. LPS, lipopolysaccharide.

unclear whether the artificial increase of $\mathrm{CO}$ could benefit critically ill patients.

\section{Abbreviation}

CO, carbon monoxide.

\section{Competing interests}

MJD is a recipient of an AGIKO grant of the Netherlands Organization for Health Research and Development (ZonMw).

\section{Author details}

'Department of Intensive Care, Radboud University Nijmegen Medical Centre, Geert Grooteplein-zuid 10, 6525 GA Nijmegen, The Netherlands. ${ }^{2}$ Department of Pharmacology and Toxicology, Radboud University Nijmegen Medical Centre, Geert Grooteplein 21, 6525 EZ, Nijmegen, The Netherlands. ${ }^{3}$ Nijmegen Intitute for Infection, Inflammation and Immunity, Radboud University Nijmegen Medical Centre, Geert Grooteplein-zuid 10, 6525 GA Nijmegen, The Netherlands. 


\section{Published: 23 April 2012}

\section{References}

1. Fazekas AS, Wewalka M, Zauner C, Funk GC: Carboxyhemoglobin levels in medical intensive care patients: a retrospective, observational study. Crit Care 2012, 16:R6

2. Morimatsu H, Takahashi T, Matsusaki T, Hayashi M, Matsumi J, Shimizu H, Matsumi M, Morita K: An increase in exhaled CO concentration in systemic inflammation/sepsis. J Breath Res 2010, 4:047103.

3. Cove ME, Pinsky MR: Carboxyhemoglobin levels in medical intensive care patients. Crit Care 2012, 16:411.
4. Suffredini AF, Hochstein HD, McMahon FG: Dose-related inflammatory effects of intravenous endotoxin in humans: evaluation of a new clinical lot of Escherichia coli O:113 endotoxin. J Infect Dis 1999, 179:1278-1282.

5. Mayr FB, Spiel A, Leitner J, Marsik C, Germann P, Ullrich R, Wagner O, Jilma B:

Effects of carbon monoxide inhalation during experimental endotoxemia in humans. Am J Respir Crit Care Med 2005, 171:354-360.

\section{doi:10.1186/cc11295}

Cite this article as: Dorresteijn MJ, Pickkers P: Carboxyhemoglobin levels during human inflammation. Critical Care 2012, 16:424 